\title{
Trends in inflammatory bowel disease therapy
}

$\mathrm{F}$ ALK SYMPOSIUM No. 66, TRENDS IN INFLAMMATORY BOWEL disease therapy 1992, comprised six sessions over three days and attracted more than 400 participants. The first session, "Progress in the pathogenesis of IBD", comprised eight sessions, including: "Genetics and epidemiology", "Neuropeptides", "Granuloma formation", "Intestinal macrophages", "T cell-induced mucosal changes", "Complement deposition", "Autoimmunity", and an overview, "Progress in pathogenesis."

The second session concerned "Pathogenesis and pharmaceutics", in an attempt to link prescription of drugs directly to interfere with pathogenic mechanisms. This session comprised "Immunosuppressive therapy", "Inflammation mediator blockers", "Corticosteroid therapy: Old and new", and "Anti-infectious therapy".

The third session addressed "IBD epidemiology and diagnosis: Ongoing issues and new ideas". This involved six speakers giving their perspectives on "Epidemiology: Unanswered questions from Europe, and from Canada, IBD in a defined North American population", "A quality of life index for IBD", "IBD and NSAIDs", and "Indeterminate colitides".

The fourth session on "Therapy of acute episodes of IBD was introduced by a debate, "Are placebo trials ethical in IBD therapy?" followed by four topics; "5-ASA therapy in IBD: What is new since 1990?", "Gut toxicity of 5-ASA", "Interleukins and IBD", and "Prostaglandins in IBD Therapy". There were four discussions in ulcerative colitis; "Lidocaine as topical treatment of distal ulcerative colitis", "Zileuton: A placebo controlled trial in acute ulcerative colitis", "Immunoglobulin therapy in IBD", and "The use of cyclosporine in the treatment of severe active ulcerative colitis". There were five contributions for Crohn's disease; "Pediatric issues in IBD therapy", "Special issues in nutrition therapy", "Defined formula diets in Crohn's disease", "Elemental versus polymetric diet in Crohn's disease", and "FX506 in acute Crohn's disease".

The fifth session concerned "Recurrence and its prevention". There was an introductory session on "The problem of recurrence in Crohn's disease". There were four sessions on "Predicting recurrence", as follows: "Clinical predictors of recurrence in IBD", "The pathology of recurrence", "Immunological predictors of recurrence", and "Predicting recurrence using simple tests". The second part concerned "Managing relapse, inducing remission", with five contributions: "Prevention of relapse in ulcerative colitis using oral or topical 5-ASA therapy", "Preventing relapse in Crohn's disease", "Cyclosporine in Crohn's disease", "Comparative study of oral 4-ASA versus 5-ASA in the maintenance treatment of Crohn's disease" and "The steroid-resistant patient".

Finally, "Controversies in the surgical management of IBD" was the topic of session VI. There were six contributions, "Crohn's disease: The benefits of extensive surgery", contrasted with "Crohn's disease: The benefits of minimal surgery", "Ileoanal pouch: Mucosectomy essential?", "Ileoanal pouches: Mucosectomy unnecessary?", "Perianal Crohn's disease: Conservative approach", and "Perianal Crohn's disease: Active approach".

There were thirty-nine papers received and accepted for this issue.

F Martin, MD, FRCPC, Chairman $R$ McLeod, MD, FRCPC LR Sutherland, MD, FRCPC CN Williams, MD, FRCPC Scientific Organizing Committee 


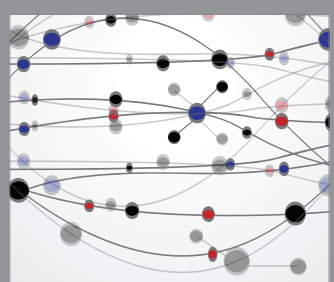

The Scientific World Journal
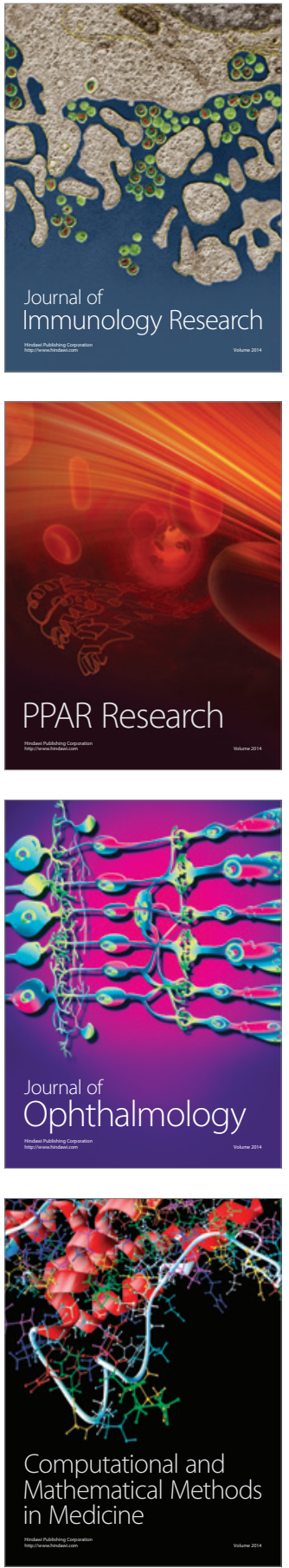

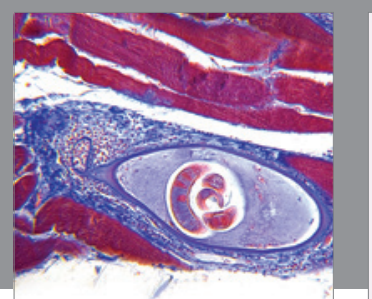

Gastroenterology Research and Practice

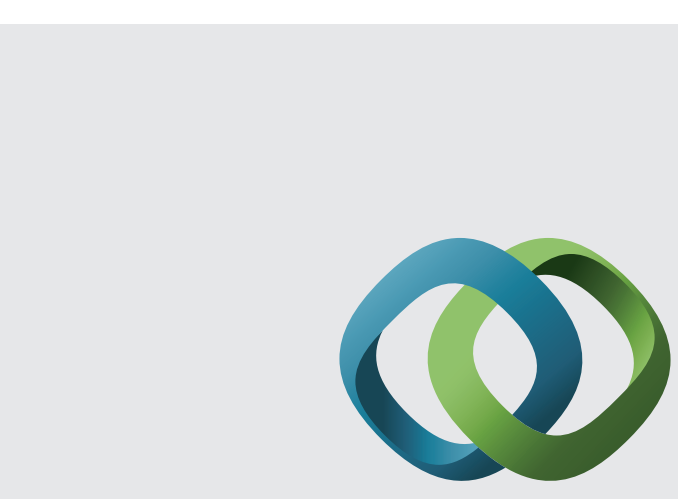

\section{Hindawi}

Submit your manuscripts at

http://www.hindawi.com
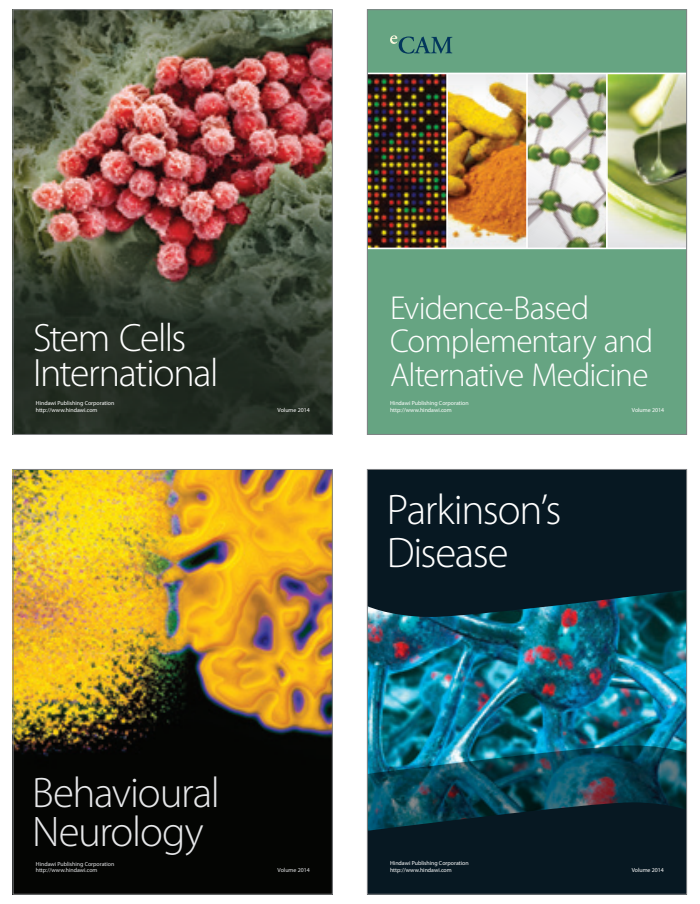
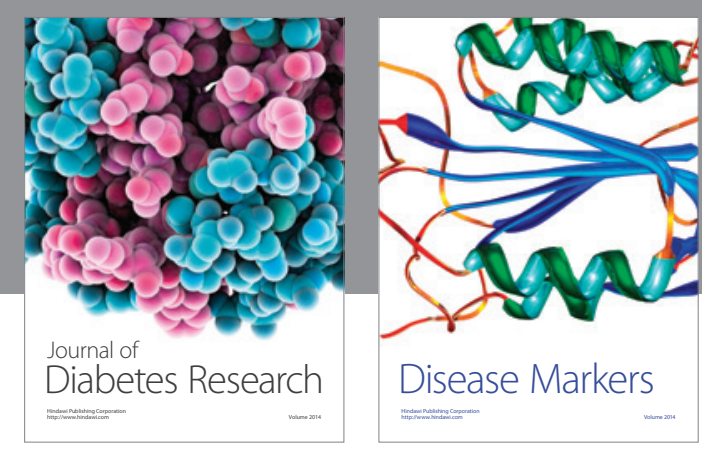

Disease Markers
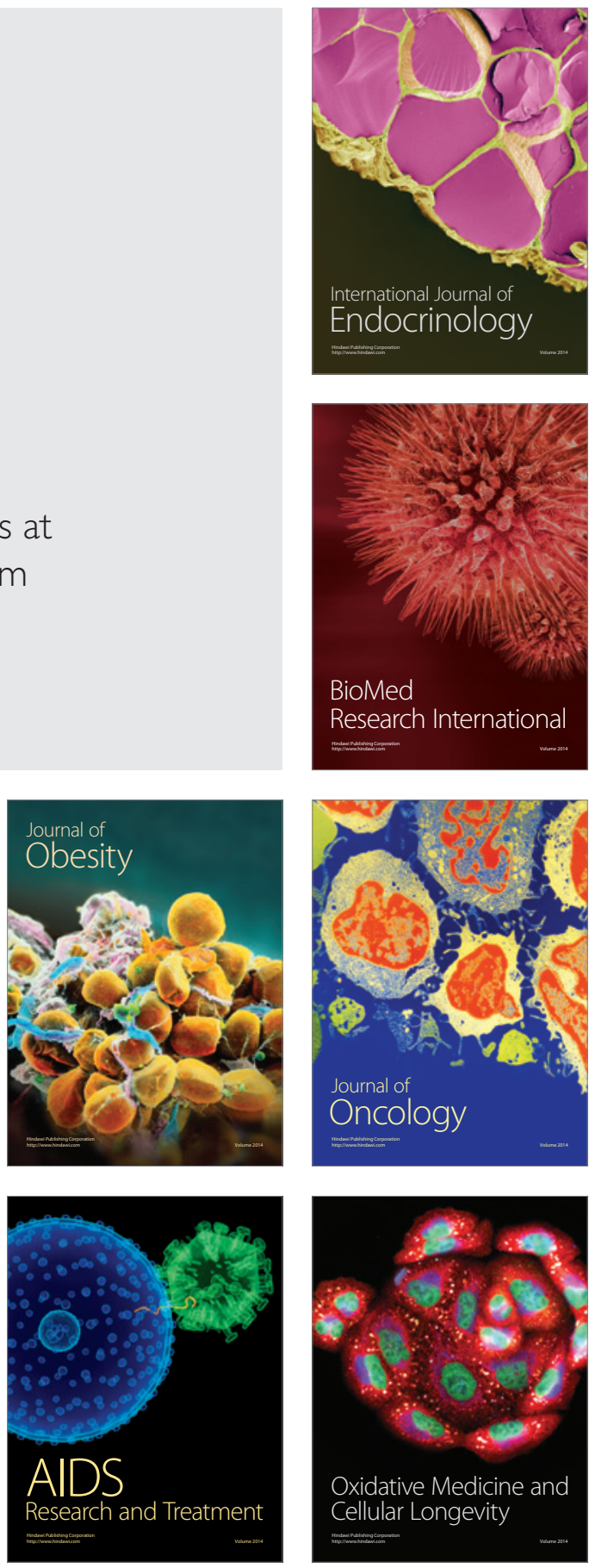